\title{
PDE4 inhibition enhances hippocampal synaptic plasticity in vivo and rescues MK801-induced impairment of long-term potentiation and object recognition memory in an animal model of psychosis
}

\author{
V Wiescholleck ${ }^{1,2}$ and D Manahan-Vaughan ${ }^{1,2}$
}

Inhibition of phosphodiesterase type 4 (PDE4) by rolipram (4-(3-(cyclopentyloxy)-4-methoxyphenyl)-pyrrolidin-2-one) has been the focus of many behavioral and molecular studies in the recent years. Rolipram exhibits memory-enhancing effects in rodents. In vitro studies have shown that long-term potentiation (LTP), which may comprise a cellular substrate for learning, is also enhanced by rolipram. However, effects have not been assessed in vivo. Rolipram has antipsychotic properties. Psychosis affects cognition and in animal models of psychosis LTP is impaired. In this study, we investigated if PDE4 inhibition improves LTP in healthy animals in vivo and if PDE4 inhibition rescues impaired LTP and prevents object recognition memory deficits in an animal model of psychosis. Recordings were made from the hippocampus of adult, freely behaving Wistar rats. Thirty minutes after treatment with rolipram or vehicle, a tetanus was applied to the medial perforant path to elicit short-term potentiation (STP) in the dentate gyrus. At this time-point, radioimmunoassay revealed that rolipram significantly elevated cyclic adenosine monophosphate levels in the dorsal hippocampus, in line with reports by others that rolipram mediates decreased PDE4 activity. In healthy animals, both intracerebroventricular and subcutaneous treatment with rolipram facilitated STP into LTP, suggesting that PDE4 inhibition may have a permissive role in plasticity mechanisms that are relevant for learning and memory. One week after a single systemic treatment with the irreversible $\mathrm{N}$-methyl-D-aspartate antagonist, MK801, LTP and object recognition memory were significantly impaired, but could be rescued by PDE4 inhibition. These data suggest that the relief of cognitive disturbances in psychosis models by rolipram may be mediated in part by a rescue of hippocampal LTP.

Translational Psychiatry (2012) 2, e89; doi:10.1038/tp.2012.17; published online 13 March 2012

Introduction

Inhibition of the phosphodiesterase type 4 (PDE4) by rolipram (4-3-Cyclopentyloxy)-4-methoxyphenyl)-pyrrolidin-2-one) enhances cognition in animals. Several studies have demonstrated that rolipram improves animals' performance in memory-dependent behavioral tests, such as the object recognition task (ORT) ${ }^{1}$ and freezing-to-context task. ${ }^{2}$ It selectively inhibits PDE4, which comprises a family of four enzymes (PDE4A-D) that control the hydrolysis of cyclic adenosine monophosphate (cAMP). Consequently, PDE4 inhibition reduces degradation of $C A M P$, and therefore leads to elevated cAMP levels. ${ }^{2,3}$ cAMP is a second messenger that has a key role in several intracellular cascades, including the cAMP/ protein kinase A (PKA)/ cAMP response elementbinding protein (CREB) pathway. ${ }^{4}$ The cAMP/PKA/CREB pathway has been shown to be critically involved in learning and memory. ${ }^{5}$
In vitro studies in CA1 region have further demonstrated that rolipram facilitates long-term potentiation (LTP) in hippocampal slice preparations. ${ }^{2,6}$ LTP comprises an activitydependent long-lasting strengthening of synaptic transmission. ${ }^{7}$ Hippocampal LTP has been proposed to be a cellular mechanism underlying learning and memory. ${ }^{8,9}$ Interestingly, besides being involved in learning and memory, the cAMP/ PKA/CREB pathway is also crucial for LTP and transcription of LTP-related genes. ${ }^{4}$ Hence, cognition improvement via PDE4 inhibiton might be due to the modulation of this pathway and subsequent enhancement in the ability to express synaptic plasticity. However, the question as to whether rolipram also facilitates LTP in intact brains of healthy freely moving animals has not yet been answered.

Cognition is impaired under many pathological conditions, one of which is psychosis. Although acute psychotic events occur extremely frequently-3 out of 100 people will experience a psychotic episode in their lifetimes-its pathophysiology and

\footnotetext{
${ }^{1}$ Medical Faculty, Department of Neurophysiology, Ruhr University Bochum, Bochum, Germany and ${ }^{2}$ International Graduate School of Neuroscience, Ruhr University Bochum, Bochum, Germany

Correspondence: Professor D Manahan-Vaughan, Medical Faculty, Department of Neurophysiology, Ruhr University Bochum, MA 4/149, Universitaetsstr. 150, 44780 Bochum, Germany.
}

E-mail: denise.manahan-vaughan@ rub.de

Keywords: in vivo; long-term potentiation; MK801; PDE4 inhibition; rolipram; schizophrenia

Received 25 July 2011; revised 13 January 2012; accepted 15 January 2012 
long-term consequences are not well understood. Acute psychotic episodes can be caused under various conditions, such as for example, schizophrenia, bipolar disorder, schizophreniform disorder, schizoaffective disorder, drug-induced psychosis, brief reactive psychosis, organic psychoses and delusional disorder. ${ }^{10}$ Single psychotic events must be appropriately treated in order to prevent long-term consequences. Recent psychiatric research indicates that there is a critical period after first-episode psychosis, where early intervention is crucial. ${ }^{11-13}$ If treated successfully, there is a higher chance of preventing secondary morbidity, relapse or persistent disability associated with, for example, schizophrenia-related disorders. ${ }^{14}$

To study the cellular and molecular mechanisms underlying single psychotic events, an animal model of acute psychosis was developed in which a single injection of the irreversible uncompetitive $\mathrm{N}$-methyl-d-aspartate receptor (NMDAR)antagonist, MK801, is applied systemically in rats. ${ }^{15-17}$ Uncompetitive NMDAR-antagonists have been shown to induce psychotic symptoms in healthy humans and to exacerbate symptoms of schizophrenic patients. ${ }^{18,19}$ After a single injection with MK801, rats display short-lasting transient behavioral aspects of psychosis-related behavior, such as disturbed pre-pulse inhibition of the acoustic startle response, disturbed stereotypy and increased ataxia. ${ }^{15,16}$ This is followed by long-term impairments in both spatial memory and in LTP at the perforant path-dentate gyrus synapse of the hippocampus. ${ }^{16}$ These findings suggest that long-term disruptions in cognitive ability in psychosis are associated with the loss of LTP.

Recent evidence indicates that alterations in the activity of PDE4 may contribute to the cellular mechanisms underlying psychosis. ${ }^{20-22}$ PDE4B has been shown to bind with a protein called DISC1 (disrupted in schizophrenia 1). ${ }^{23}$ Chromosomal aberrations of DISC1 clearly correlate to schizophrenia. ${ }^{24,25}$ DISC1 shows reduced expression in psychotic patients, thereby probably mediating less binding of the dephosphorylated inactive PDE4B and a subsequent pathological elevation of the amount of phosphorylated active PDE4B. ${ }^{26}$ Thus, PDE4B activity seems to be directly regulated by $D I S C 1^{27}$ and therefore may have an important role in psychosis-related diseases.

In this study, we asked the question as to whether PDE4 inhibition may enable a rescue of LTP and memory performance in MK801-treated animals. This is not so unreasonable, given reports that rolipram has attenuating effects on MK801-induced impairments in psychosis-related behavior of rodents, ${ }^{20,21,28,29}$ indicating that PDE4 might act as a possible new receptorindependent therapeutic target in psychotic disorders by directly affecting PDE4-specific cAMP hydrolysis.

We first addressed the question as to whether rolipram treatment of adult freely behaving rats results in an enhancement of LTP in healthy animals, as this has not yet been explored in vivo. We then examined if PDE4 inhibition rescues LTP that is impaired in the MK801 animal model of psychosis. Next, to validate a peripheral route of application, we investigated if the plasticity-enhancing effects of an intracerebroventricular rolipram injection can be replicated by systemic treatment. And finally, in order to examine functional aspects of our electrophysiological findings, we assessed the effect of rolipram on object recognition memory performance in control and MK801-treated animals.

\section{Materials and methods}

The present study was carried out in accordance with the European Communities Council Directive of 24 November 1986 (86/609/EEC) for care of laboratory animals and after approval of the local ethic committee (senate of Berlin or Bezirksamt Arnsberg). All efforts were made to reduce the number of animals used.

Animals. Six to seven-week-old male Wistar rats (Charles River, Sulzfeld, Germany) were housed on a 12-h light/ dark cycle (lights on at 07:00 AM) for at least 1 week after their arrival in the animal facilities before treatment and surgery.

Surgical implantations. Animals (7-8 weeks old) were anesthetized $\left(52 \mathrm{mg} \mathrm{kg}^{-1}\right.$ pentobarbital via intraperitoneal (i.p.) injection) and underwent chronic implantation of a monopolar recording electrode in the granule cell layer of dentate gyrus (hole diameter: ca. $1 \mathrm{~mm}$; hole coordinates: $3.1 \mathrm{~mm}$ posterior to bregma, $1.9 \mathrm{~mm}$ lateral to the midline; electrode depth: ca. $4.2 \mathrm{~mm}$ from bone) and a bipolar stimulating electrode in the perforant pathway (hole diameter: $1 \mathrm{~mm}$ diameter; hole coordinates: $6.9 \mathrm{~mm}$ posterior to bregma, $4.1 \mathrm{~mm}$ lateral to the midline; electrode depth: ca. $4.0 \mathrm{~mm}$ from bone), as described previously. ${ }^{30}$ The perforant pathway-dentate gyrus synapse was selected in line with previous studies of LTP in this animal model of psychosis conducted by our group. ${ }^{16,17}$ In addition, in terms of certain schizophrenia-relevant GABAergic markers, the dentate gyrus has been shown to react first to systemically applied MK801 as compared with all other hippocampal subfields and brain regions. ${ }^{31}$ Both electrodes were made of polyurethane-coated stainless steel wire. A cannula was implanted in the lateral cerebral ventricle $(0.5 \mathrm{~mm}$ posterior to bregma, $1.6 \mathrm{~mm}$ lateral to the midline, $5.6 \mathrm{~mm}$ length, $0.8 \mathrm{~mm}$ diameter, $4 \mathrm{~mm}$ depth) to enable injections. The animals were allowed to recover from surgery for 7-10 days before experiments were conducted. Animals which then showed evoked potentials that are not characteristic of the medial perforant path-dentate gyrus synapse were excluded from the study.

Electrophysiological recordings. Throughout all experiments, the animals could move freely within the recording chamber $(40 \times 40 \times 40 \mathrm{~cm})$ and had free access to food and water. For acclimatization the animals were transferred to the experiment room 1 day in advance. The implanted electrodes were connected through a head stage by a flexible cable and a swivel connector to the stimulation unit and amplifier. Recordings were stored on a personal computer.

Responses were evoked by stimulating at low frequency ( $0.025 \mathrm{~Hz}, 0.2 \mathrm{~ms}$ stimulus duration, $10000 \mathrm{~Hz}$ sample rate). For each time-point, five evoked responses were averaged. Dentate gyrus population spike (PS) amplitude, as well as field excitatory postsynaptic potential (fEPSP) slope were monitored: PS amplitude reflects summated action potentials from the somatic layer of granule cells in the dentate gyrus, 
whereas alterations of fEPSP indicate dendritic changes. Each experiment started with an input-output curve (100$900 \mu \mathrm{A}$ in steps of $100 \mu \mathrm{A}$ ) to determine the stimulus intensity required to elicit a PS that was $40 \%$ of the maximum obtained. To ensure stability of recordings and to assess basal synaptic transmission, all animals were tested in a baseline experiment first, where only test-pulse stimulation was applied. LTP was induced by high-frequency stimulation (HFS) (10 bursts of 15 pulses at $200 \mathrm{~Hz}$ with a $10 \mathrm{~s}$ inter-burst interval). Short-term potentiation (STP) was induced by a weak HFS (wHFS, 3 bursts of 15 pulses at $200 \mathrm{~Hz}$ and a $10 \mathrm{~s}$ inter-burst interval).

At the beginning of each experiment, baseline PS amplitude and fEPSP slope were obtained by averaging the response to stimulation (five sweeps at $40 \mathrm{~s}$ intervals), every $5 \mathrm{~min}$ over a period of $30 \mathrm{~min}$. Drug or vehicle injections were then applied either via an intracerebroventricular cannula at the site ipsilateral to electrophysiological recordings, or subcutaneously (s.c.). Injections were followed by additional six recordings in a 30-min or 60-min period. At this point, HFS or wHFS was given (no HFS/wHFS stimulation in baseline experiments), and three additional measurements at 5-min intervals were taken, followed by recordings at $15-\mathrm{min}$ intervals for $24 \mathrm{~h}$.

Histology. At the end of the electrophysiological study, brains were removed and histological verification of electrodes and cannula localization was carried out. Brain sections $(16 \mu \mathrm{m})$ were stained according to the Nissl method using $1 \%$ toluidine blue and then examined using a light microscope. Data from animals in which an incorrect electrode or cannula localization was found, or where hippocampal misformations were evident were excluded from the study.

CAMP radioimmunoassay. Right dorsal hippocampi were dissected $30 \mathrm{~min}$ after an intracerebroventricular (i.c.v.) injection of $5 \mu \mathrm{l}$ of either vehicle or rolipram $(2.75 \mu \mathrm{g})$, and were then shock-frozen in liquid nitrogen before being stored at $-80^{\circ} \mathrm{C}$. The tissue was subsequently homogenized in $1 \mathrm{ml}$ ice-cold $70 \%$ ethanol and centrifuged for $15 \mathrm{~min}$ at $4{ }^{\circ} \mathrm{C}$ and 15300 r.p.m. The supernatants were used for the cAMP radioimmunoassay and the pellets were kept for quantification of protein amount via the bicinchoninic acid (BCA) method, performed according to kit instructions (BCA protein assay kit, Pierce, Thermo Scientific, Rockford, IL, USA). The cAMP-radioimmunoassay (IBL international $\mathrm{GMBH}$, Hamburg, Germany), based on the principle of radioimmunoassays for cyclic nucleotides described by Steiner et al. ${ }^{32}$ and modified by Harper and Brooker, ${ }^{33}$ was performed according to kit instructions. In brief, the supernatant of each sample was dried via vaporization and subsequently diluted in $100 \mu \mathrm{l}$ radioimmunoassay buffer (100 mM sodium acetate, $\mathrm{pH}$ 6.0) and acetylated with triethylamine and acetate hydride (2:1). Samples were incubated for $3 \mathrm{~h}$ with ${ }^{125}$ I-labeled cAMP and the preprecipitated antiserum. As radioactive and non-radioactive antigens compete for a fixed number of antibody-binding sites, the amount of ${ }^{125}$-labeled antigen bound to the antibody is inversely proportional to the analyzed concentration of the sample. The reaction was stopped by the addition of a co-precipitating solution and a centrifugation step. The precipitate was counted in a gamma counter (Cobra II Auto-Gamma Counter, Packard GMI, USA). cAMP levels were normalized to the amount of protein in the pellet.

Object recognition task. The ORT was performed as described elsewhere. ${ }^{34}$ The apparatus consisted of a grey square polyvinyl chloride arena $(80 \times 80 \times 80 \mathrm{~cm})$. The test was performed with a constant light intensity of 18 lux. Two different kinds of objects were used: a black polyvinyl rectangle tower $(9 \times 11 \times 23 \mathrm{~cm})$ and a transparent glass cylinder $(10 \mathrm{~cm}$ diameter, $30 \mathrm{~cm}$ height). The objects could not be displaced by the animals, as they were weighted with sand or stones.

Three habituation sessions preceded the test, in which the animals were allowed to explore the empty arena for $5 \mathrm{~min}$ each. The testing was carried out directly after the last habituation session. The testing comprised two trials of 3-min duration each. A rat was always placed into arena facing the middle of the front wall. During the first trial (T1) an animal was allowed to explore two identical objects, which were placed symmetrically $20 \mathrm{~cm}$ away from the walls, After T1 the rat was put back into its home cage. After $4 \mathrm{~h}$ the second trial (T2) took place, in which the rat was placed back into the arena and exposed to a familiar and a novel object (Figure 5a). The testing session was videotaped. The times spent exploring each object during T1 and T2 were scored manually. Exploration was defined as directing the nose to the object at a distance of no more than $2 \mathrm{~cm}$ and/or touching the object with the nose. Sitting on the object was not considered as exploratory behavior. In order to avoid the presence of olfactory cues the objects and the arena were always thoroughly cleaned with $70 \%$ ethanol, washed with water and dried before each trial. Furthermore, as the objects were available in triplicate, neither of the two identical objects from $\mathrm{T} 1$ had to be reused in T2. All combinations and locations of objects were used in a balanced manner to reduce potential biases, such as preferences for particular locations or objects. In addition, total exploration times have been compared between groups in T1 and T2 in order to exclude potential exploration bias. The testing order was determined randomly. Rats that did not explore any of the objects in any trial were removed from analysis.

Compounds and drug treatment. The PDE4 inhibitor rolipram (4-3-Cyclopentyloxy)-4-methoxyphenyl)-pyrrolidin2-one) (Biozol, Eching, Germany) was dissolved in 1.5\% dimethylsulfoxide (DMSO) or in $3 \%$ DMSO and $0.9 \%$ physiological saline for i.c.v injection or for systemic injection, respectively. Dilutions of 1.5 or $3 \%$ DMSO had no effect on control recordings. For i.c.v injections, rolipram $(2.75 \mu \mathrm{g}$ or $5.5 \mu \mathrm{g})$ or vehicle was injected in a $5 \mu \mathrm{l}$ volume over a 5 -min period via a Hamilton syringe $30 \mathrm{~min}$ before stimulation to enable diffusion from the lateral cerebral ventricle to the hippocampus to occur. For systemic application, comparable concentrations were calculated, based on known pharmacokinetics of rolipram in the rat (Krause and Kühne, 1988). Rolipram $\left(0.6 \mathrm{mg} \mathrm{kg}^{-1}\right.$ or $\left.1.2 \mathrm{mg} \mathrm{kg}^{-1}\right)$ or vehicle $\left(2 \mathrm{ml} \mathrm{kg}^{-1}\right)$ were injected s.c. 30 or 
$60 \mathrm{~min}$ before stimulation. Systemic injection of the higher dose $\left(1.2 \mathrm{mg} \mathrm{kg}^{-1}\right)$ caused transient dizziness and catalepsy in the animals, which disappeared approximately $20 \mathrm{~min}$ after treatment. In behavioral experiments, rolipram $\left(1.2 \mathrm{mg} \mathrm{kg}^{-1}\right)$ was injected s.c. $24 \mathrm{~h}$ before T2 (Figure 5a), as with this concentration LTP was significantly enhanced for at least $24 \mathrm{~h}$. Furthermore, acute stress effects arising from the injection could thus be excluded.

The NMDAR antagonist [+]-5-methyl-10,11-dihydro5Hdibenzo-[a,d]-cyclohepten-5,10-imine hydrogen maleate (MK801, Tocris, Bristol, UK) was dissolved in 0.9\% physiological saline. MK801 $\left(5 \mathrm{mg} \mathrm{kg}^{-1}\right)$ or vehicle $\left(10 \mathrm{ml} \mathrm{kg}^{-1}\right)$ were injected i.p. 7 days before commencement of experiments. The concentration of MK801 was chosen in accordance with previous studies conducted by our group. ${ }^{15-17}$ Directly after injection, acute transient psychosis-like behaviors (locomotion, ataxia and stereotypy) were scored as described elsewhere ${ }^{15}$ in order to evaluate the effectiveness of the treatment. Animals that did not display this psychosis-like behavioral profile were excluded from further experiments.

Data analysis. In all electrophysiological experiments, data were expressed as mean \% pre-injection values \pm standard error of the mean (s.e.m.). Analysis of variance (ANOVA) was used to evaluate differences between groups in the both control animals studies (i.c.v. and s.c. control studies). The Bonferroni post-hoc test was applied, if more than two groups were compared. ANOVA with repeated measures was used to evaluate differences between pretreatment control experiments and experiments in which test compound or vehicle was applied intracerebrally in the MK801 study. Therefore, all values after stimulation (weak HFS or HFS) or corresponding values in baseline experiments were compared. In the cAMP assay, quantitative cAMP values for the vehicle and the rolipram groups have been analyzed via a one-way ANOVA. In the behavioral study percentage of total exploration time for each object during T1 and T2 were calculated. One-way ANOVA was used in order to compare percentage of time spent in exploring the novel as compared with the familiar object during T2 for each of the four groups. Differences in total exploration times in T1 and T2 have been analyzed via a one-way ANOVA. Statistical analysis was performed using the SPSS software (version 11.5). The level of significance was set at $P<0.05$.

\section{Results}

PDE4 inhibition facilitates STP into LTP in vivo, but does not affect basal synaptic transmission. To date, effects of PDE4 inhibitors on hippocampal synaptic plasticity have only been studied in vitro. $2,6,35$ We investigated whether an i.c.v. injection with the PDE4 inhibitor, rolipram, leads to alterations in excitability or in ability to express synaptic potentiation in the dentate gyrus of adult freely behaving rats. Basal synaptic transmission was unaffected by rolipram, as no significant changes were found between vehicle-treated control animals $(n=6)$ and animals treated with rolipram $(5.5 \mu \mathrm{g}, n=6)$ in a baseline experiment
(PS: $F(1,228)=0.780$, not significant (NS), Figure 1a; fEPSP: $F(1,229)=1.311$, NS, Figure $1 b)$.

In control animals $(n=6)$, weak HFS (wHFS: 3 bursts of 15 pulses at $200 \mathrm{~Hz}, 10 \mathrm{~s}$ interburst interval) elicited STP that persisted for approximately $2 \mathrm{~h}$. Intracerebral treatment with rolipram significantly facilitated STP into LTP (PS: $F(2,300)=14.322, P<0.0001$, Figure 1c; fEPSP: $F$ $(2,304)=19.230, P<0.0001$, Figure $1 d)$. The subsequent Bonferroni post-hoc test revealed a significant increase in potentiation of the PS amplitude after application of both, $2.75 \mu \mathrm{g}(P<0.01, n=4)$ and $5.5 \mu \mathrm{g}(P<0.0001, n=6)$ of rolipram, as compared with the control group. The same posthoc analysis of the fEPSP revealed a significantly enhanced potentiation if the higher $(P<0.0001)$, but not the lower dose of rolipram was used. If only the values recorded in the last hour of the experiment (24-25h after stimulation) were included in the analysis, there was still a significant effect of treatment (PS: $F(2,59)=6.657, P<0.01$; fEPSP: $F$ $(2,60)=14.327, P<0.0001)$. In this case, the post-hoc test showed a significantly increased PS amplitude $(P<0.01)$ and fEPSP $(P<0.0001)$ for the higher dose $(5.5 \mu \mathrm{g})$ only, whereas neither PS amplitude nor fEPSP were different from control after lower dose $(2.75 \mu \mathrm{g})$ treatment. Thus, although both doses were effective, the synaptic potentiation enabled by the higher dose lasted longer. In conclusion, PDE4 inhibition facilitates STP into persistent LTP in vivo, but does not affect basal synaptic transmission.

Intracerebroventricular (i.c.v.) injection of the PDE4 inhibitor rolipram elevates cAMP levels in the hippocampus $30 \mathrm{~min}$ after application. In our plasticity experiments, the afferent fibers to the hippocampus were stimulated $30 \mathrm{~min}$ after application of rolipram. Rolipram has been shown to elevate cAMP levels when given to the hippocampal slice preparation. This occurs as a direct consequence of rolipram-mediated decreased PDE4 activity. ${ }^{36}$ To check that this is also the case in vivo and within the time-frame of our plasticity experiment, we assessed if cAMP levels were altered after treatment with rolipram. We observed that the cAMP concentration in the dorsal hippocampus, $30 \mathrm{~min}$ after i.c.v. treatment with rolipram $(2.75 \mu \mathrm{g})(n=5)$, was significantly higher ( $\mathrm{F}$ $(1,8)=11646, \quad P<0.01$; Figure 1f) as compared with vehicle-treated animals $(n=5)$. Thus, at the time-point of stimulation rolipram had diffused adequately to the hippocampus and had efficiently decreased PDE4 activity.

PDE4 inhibition rescues impaired LTP 1 week after an acute MK801 injection. In controls, we first showed that systemic (i.p.) treatment with vehicle does not have any effect on the expression of LTP. HFS (10 bursts of 15 pulses at $200 \mathrm{~Hz}, 10 \mathrm{~s}$ interburst interval) was used to elicit LTP that lasted for over $24 \mathrm{~h}$. Here, no differences were found between pretreatment control LTP and LTP induced 1 week after i.p. treatment with vehicle $(n=7)$ (PS: $F$ $(1,159)=1.115$, NS, Figure 2a; fEPSP: $F(1,159)=0.006$, NS, not shown). In both experiments, application of HFS resulted in a significant potentiation of synaptic strength that lasted for at least $24 \mathrm{~h}$. 

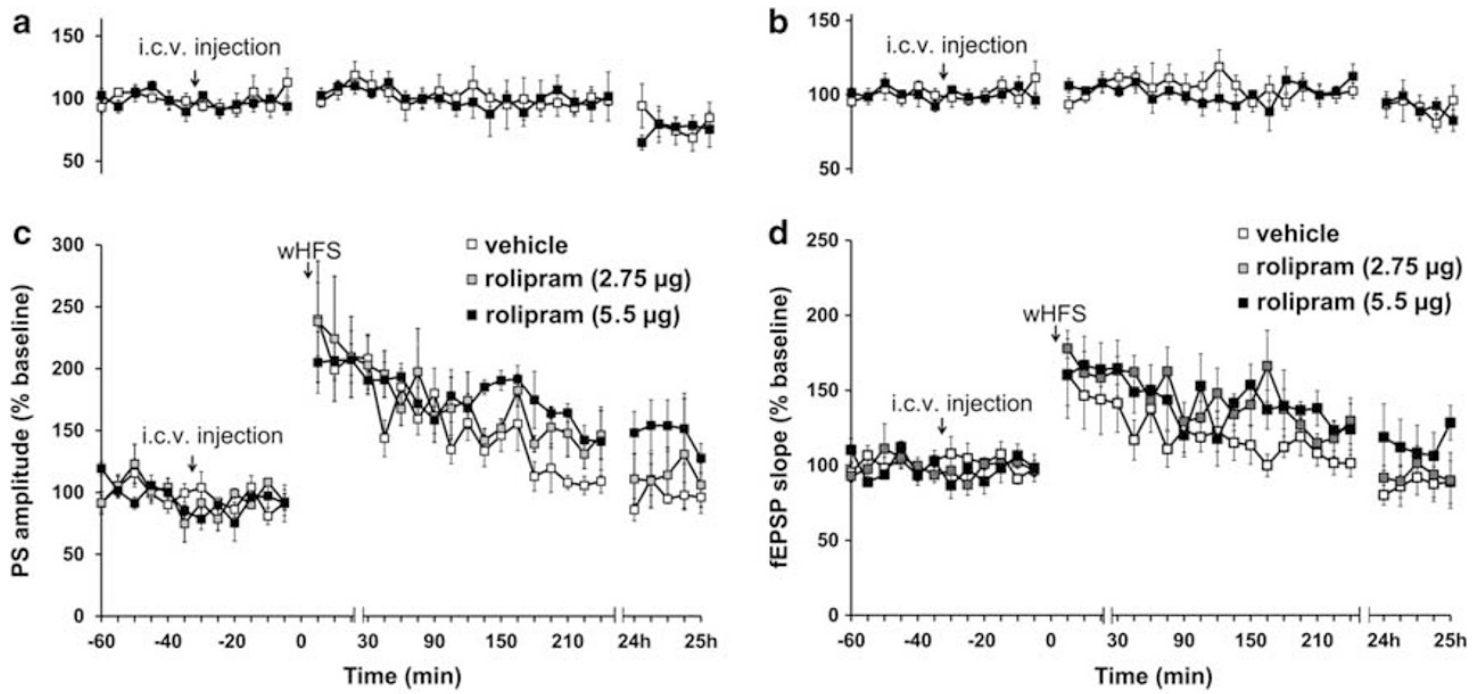

e
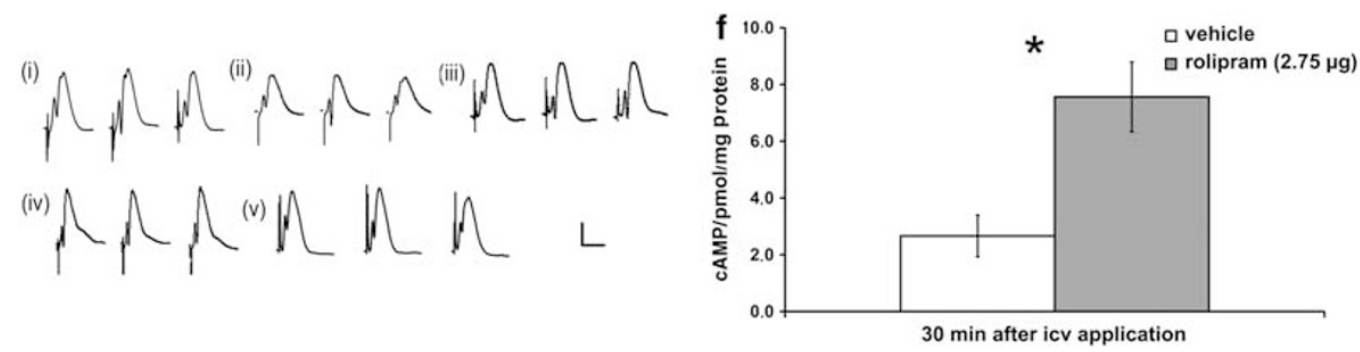

Figure 1 PDE4 inhibition facilitates STP into LTP, but does not affect basal synaptic transmission in the dentate gyrus in vivo. Basal synaptic transmission is unaffected by PDE4 inhibition elicited i.c.v. No differences in PS amplitude (a) or in fEPSP (b) occur between vehicle- (white squares) and rolipram-treated (black squares) rats in response to test-pulse stimulation. Line breaks on the $x$-axis indicate change in time-scale. (c) Weak HFS (wHFS) results in STP of the PS and fEPSP (d) in vehicle-treated animals (white squares), which lasts for approximately $2 \mathrm{~h}$. i.c.v treatment with rolipram ( $2.75 \mu \mathrm{g}$, grey squares), $30 \mathrm{~min}$ before wHFS, extends synaptic potentiation to at least $4 \mathrm{~h}$. LTP that lasts over $24 \mathrm{~h}$ is enabled, if the higher dose of rolipram $(5.5 \mu \mathrm{g}$, black squares) is applied i.c.v. Line breaks on the $x$-axis indicate change in time-scale. (e) Original analog traces show field potentials evoked from the dentate gyrus during (i) wHFS with vehicle injection, (ii) wHFS in the presence of the lower dose of rolipram, (iii) wHFS in the presence of the higher dose of rolipram, (iv) test-pulse stimulation with vehicle injection and (v) test-pulse stimulation with the higher dose of rolipram. Analogs were obtained at similar time points ( $10 \mathrm{~min}$ pre-wHFS, $10 \mathrm{~min}$ and $24 \mathrm{~h}$ post-wHFS). Vertical scale-bar corresponds to $5 \mathrm{mV}$, horizontal scale-bar to $10 \mathrm{~ms}$. (f) i.c.v. application of rolipram leads to a significantly increased cAMP concentration in the hippocampus $30 \mathrm{~min}$ after treatment, as demonstrated by radioimmunoassay. Values represent means \pm s.e.m.; ${ }^{*} P<0.05$. fEPSP, field excitatory postsynaptic potential; HFS, high-frequency stimulation; i.c.v., intracerebroventricular; LTP, long-term potentiation; PDE4, phosphodiesterase type 4; PS, population spike; STP, short-term potentiation.

In order to replicate the long-term effects of MK801 on synaptic plasticity, that have been reported in previous studies, $^{16,17}$ a second group of animals was injected with MK801, i.p, and one week later their ability to express hippocampal LTP was assessed. In line with previous findings, systemic treatment with MK801 $(n=7)$ resulted in a significant impairment of LTP in the dentate gyrus compared with control LTP (PS: F $(1,157)=170.266, P<0.0001$, Figure 2b; fEPSP: $F$ $(1,159)=72.089, P<0.0001$, not shown). Here, a lower induction magnitude and reduced duration of LTP $(2.5 \mathrm{~h})$ were evident compared to pretreatment control LTP.

A third group of animals $(n=6)$ was treated with MK801 and 1 week later the PDE4 inhibitor rolipram $(5.5 \mu \mathrm{g})$ was applied intracerebrally $30 \mathrm{~min}$ before an attempt to induce LTP. Under control conditions, vehicle injection was applied i.c.v and here, HFS elicited LTP that lasted for over $24 \mathrm{~h}$ (Figure 2c). PDE4 inhibition prevented the MK801-induced long-term deficits in the ability to express LTP (PS: $F(1,131)=3.474$, NS, Figure 2c; fEPSP: $F(1,132)=0.008$, NS, not shown). Here,
PDE4 inhibition attenuated the impairment in the induction phase and rescued fully the maintenance phase of LTP. Thus, the MK801-induced impairment in the ability to express LTP was rescued by PDE4 inhibition.

The PDE4 inhibitor, rolipram, enhances synaptic plasticity in vivo, even if applied via a systemic route. On the basis of these results, PDE4 could be considered as a therapeutic target to address, for example, cellular mechanisms of cognition in psychosis-related diseases. However, in this case, peripheral administration would be essential. In order to investigate if rolipram can also enhance plasticity if it is applied systemically, we injected either $0.6 \mathrm{mg} \mathrm{kg}^{-1}$ or a $1.2 \mathrm{mg} \mathrm{kg}^{-1}$ amount of rolipram s.c. $30 \mathrm{~min}$ before wHFS stimulation. In control animals $(n=8)$, wHFS elicited STP in the presence of a systemic application of vehicle (Figure 3a). Subcutaneous treatment with rolipram significantly facilitated STP into LTP (PS: F $(2,391)=10.999$, $P<0.0001$, Figure 3a; fEPSP: $F \quad(2,391)=20.454$, 

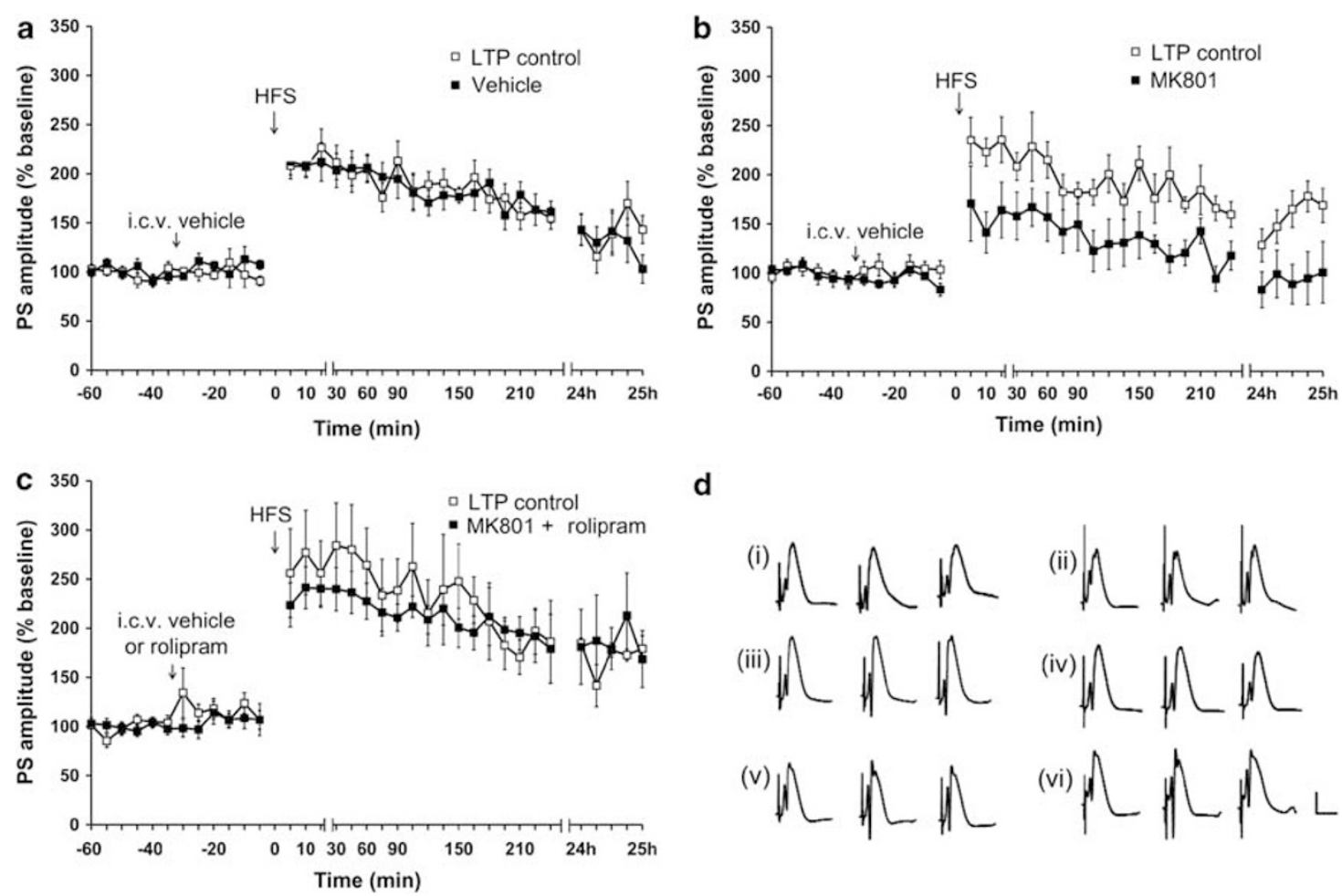

d
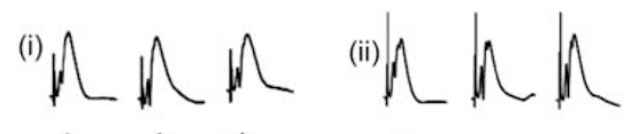

(iii)

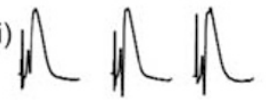

(iv) $A$

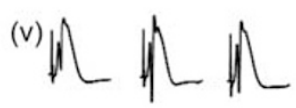

(vi)

Figure 2 PDE4 inhibition rescues impaired LTP in MK801-treated animals in vivo. (a) Systemic (i.p.) vehicle injection does not alter the profile of LTP. Control LTP, which lasts for at least $24 \mathrm{~h}$ is induced by HFS. No differences in PS occur between control LTP (white squares) and LTP elicited 1 week after a systemic vehicle treatment (black squares). Line breaks on the $x$-axis indicate change in time-scale. (b) One week after a single MK801 injection (i.p.), LTP of PS (black squares) is significantly impaired compared with control LTP (white squares). Line breaks on the $x$-axis indicate change in time-scale. (c) One week after MK801 treatment, i.c.v. application of the PDE4 inhibitor, rolipram, 30 min before HFS, fully rescues LTP (black squares). No difference in LTP profile is evident compared with control LTP (white squares). Line breaks on the $x$-axis indicate change in time-scale. (d) Original analog traces show field potentials evoked from the dentate gyrus during (i) control LTP and (ii) LTP elicited 1 week after a systemic vehicle treatment, (iii) control LTP and (iv) LTP induced one week after a systemic MK801 treatment, (v) control LTP and (v) LTP elicited 1 week after a systemic MK801 treatment in combination with rolipram. Analogs were obtained at similar time points ( $10 \mathrm{~min}$ pre-HFS, $10 \mathrm{~min}$ and $4 \mathrm{~h}$ post-HFS). Vertical scale-bar corresponds to $5 \mathrm{mV}$, horizontal scale-bar to $10 \mathrm{~ms}$. HFS, high-frequency stimulation; i.p., intraperitoneal; LTP, long-term potentiation; PDE4, phosphodiesterase type 4; PS, population spike.

$P<0.0001$, not shown). The subsequent Bonferroni post-hoc test revealed that both the lower (PS: $P<0.05$; fEPSP: $P<0.0001, n=4)$ and the higher doses (PS: $P<0.0001$; fEPSP: $P<0.0001, n=8$ ) of rolipram potentiated control STP. Thus, if applied systemically, both doses were sufficient to enhance synaptic plasticity. Analysis of the values recorded in the last hour of the experiment (24-25 h after stimulation) revealed that the higher dose is more effective (PS: $F(2,72)=5.026, P<0.01$; fEPSP: $F(2,60)=4.492$, $P<0.05)$.

Systemic application of the PDE4 inhibitor rolipram at the higher dose $\left(1.2 \mathrm{mg} \mathrm{kg}^{-1}\right)$ induces transient chemical potentiation, which lasts for $1 \mathrm{~h}$ after injection. Subcutaneous rolipram injection at the dose of $1.2 \mathrm{mg} \mathrm{kg}^{-1}$ significantly potentiated the PS amplitude and the fEPSP immediately after injection (Figure 3a) (PS: F $\quad(2,117)=12.594, \quad P<0.0001, \quad$ Figure $3 a ; \quad f E P S P$ : $\mathrm{F}(2,117)=14.185, \quad P<0.0001$, not shown). In order to study this phenomenon of chemical potentiation in more detail, a baseline experiment was performed in which either vehicle $(n=9)$ or rolipram was applied s.c. at the dose of $1.2 \mathrm{mg} \mathrm{kg}^{-1}(n=11)$. This baseline experiment revealed that
PS amplitude and fEPSP remained significantly enhanced for $1 \mathrm{~h}$ (PS: $\mathrm{F}(1,131)=66.084, P<0.0001$, Figure $3 \mathrm{~b}$; fEPSP: $\quad F \quad(1,131)=38.137, \quad P<0.0001$, not shown). Thereupon, PS amplitude and fEPSP values returned to baseline levels and remained stable for the remainder of the $25 \mathrm{~h}$ recording period. Following their return to pre-injection baseline levels, the evoked potentials were no longer different from controls (PS: $F(1,18)=0.347$, NS; fEPSP: $F$ $(1,18)=0.025$, NS). Thus, systemic injection of the higher dose of rolipram $\left(1.2 \mathrm{mg} \mathrm{kg}^{-1}\right)$ induces a transient chemical potentiation of synaptic strength.

Systemically administered rolipram facilitates STP into LTP, if wHFS is applied after synaptic transmission returns to basal levels. In this experiment (Figure 4), we waited for more than $1 \mathrm{~h}$ after the systemic application of the higher dose of rolipram $\left(1.2 \mathrm{mg} \mathrm{kg}^{-1}\right)$ before tetanic stimulation was applied. In this way, we wanted to make sure that basal synaptic transmission was comparable between controls and treated animals, when wHFS was applied. The last time-point before wHFS did not differ between controls $(n=8)$ and rolipram-treated animals $(n=8)$ (PS: $F(1,14)=1.042$, NS; Figure 4a; fEPSP: $F$ 

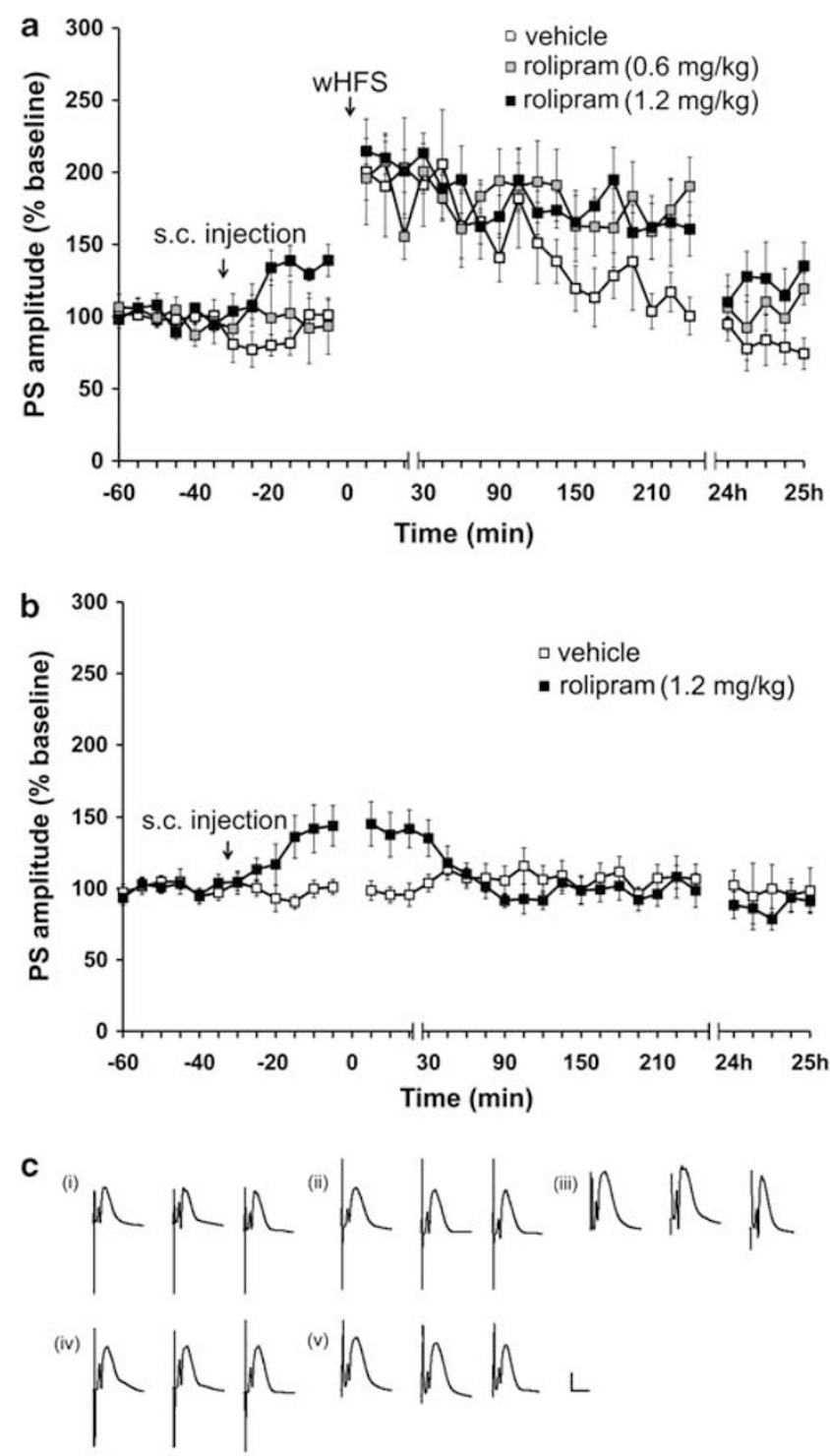

Figure 3 Systemic application of the PDE4 inhibitor rolipram enhances synaptic plasticity in vivo and transiently affects basal synaptic transmission. (a) Weak HFS (wHFS) results in STP in animals treated with vehicle s.c. (white squares). STP lasts for approximately $2 \mathrm{~h}$. S.c. treatment with the PDE4 inhibitor rolipram ( $0.6 \mathrm{mg} \mathrm{kg}^{-1}$ s.c., grey squares), $30 \mathrm{~min}$ before wHFS results in LTP, which lasts for $4 \mathrm{~h}$. LTP lasts for at least $24 \mathrm{~h}$, if the higher dose $\left(1.2 \mathrm{mg} \mathrm{kg}^{-1}\right.$, s.c., black squares) is applied. Line breaks on the $x$-axis indicate change in time-scale. (b) S.c. treatment with the higher dose of rolipram $\left(1.2 \mathrm{mg} \mathrm{kg}^{-1}\right.$, s.c., black squares) has a transient enhancing effect on the PS amplitude, which lasts for approximately $1 \mathrm{~h}$ after injection, compared with control baseline (white squares). Line breaks on the $x$-axis indicate change in time-scale. (c) Original analog traces show field potentials evoked from the dentate gyrus during (i) wHFS with s.c. vehicle injection, (ii) wHFS with s.c. injection of the low dose of rolipram, (iii) wHFS with s.c. injection of the high dose of rolipram, (iv) test-pulse stimulation with s.c. injection of vehicle and (v) testpulse stimulation with s.c. injection of the high dose of rolipram. Analogs were obtained at similar time points (10 min pre-wHFS, $10 \mathrm{~min}$ and $4 \mathrm{~h}$ post-wHFS). Vertical scale-bar corresponds to $5 \mathrm{mV}$, horizontal scale-bar to $10 \mathrm{~ms}$. HFS, highfrequency stimulation; LTP, long-term potentiation; PDE4, phosphodiesterase type 4; s.c., subcutaneously; STP, short-term potentiation.

$(1,14)=0.080$, NS, not shown). In this case, wHFS in the presence of rolipram still resulted in a significantly facilitated STP as compared with controls (PS: $F(1,352)=6.449$,

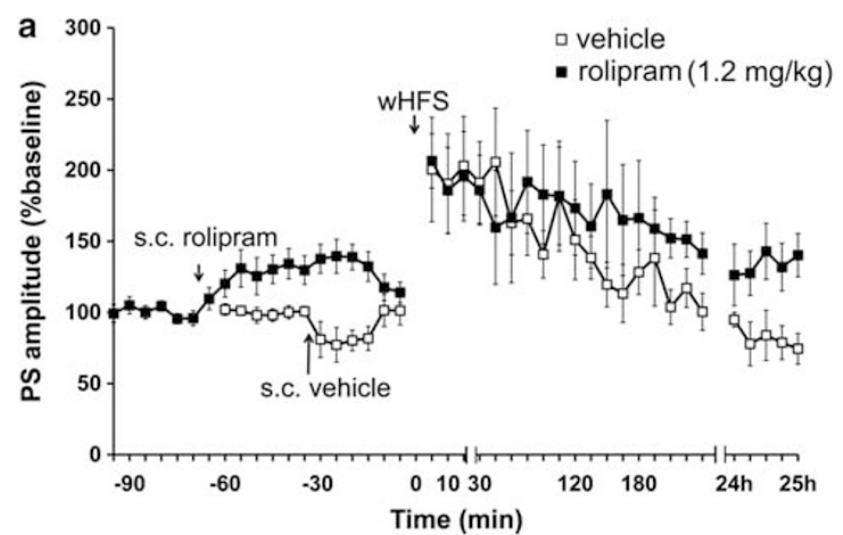

b
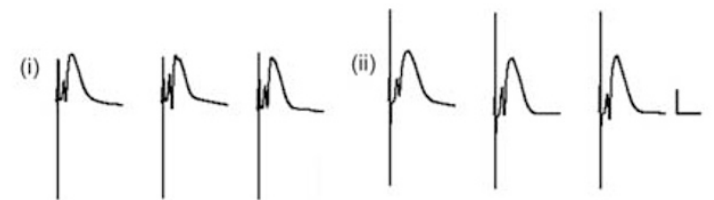

Figure 4 LTP enhancement by a subcutaneous injection of rolipram, still occurs if tetanisation is applied after the transient rolipram-mediated increase in baseline subsides. (a) To exclude that the transient increase in PS contributes to LTPfacilitation by rolipram, we examined effects on LTP after the PS enhancement had subsided. PS enhancement disappeared ca. $60 \mathrm{~min}$ after s.c. injection of rolipram. Ten minutes later wHFS was applied. Here, STP was facilitated into LTP by rolipram $\left(1.2 \mathrm{mg} \mathrm{kg}^{-1}\right.$, s.c., black squares) compared with vehicle-injected controls (white squares, the same control group as shown in Figure 3a). Line breaks on the $x$-axis indicate change in time-scale. (b) Original analog traces show field potentials evoked from the dentate gyrus during (i) wHFS with s.c. vehicle injection, (ii) wHFS with s.c. injection of rolipram $\left(1.2 \mathrm{mg} \mathrm{kg}^{-1}\right)$. Analogs were obtained at similar time points (10 min pre-wHFS, $10 \mathrm{~min}$ and $4 \mathrm{~h}$ post-wHFS). Vertical scale-bar corresponds to $5 \mathrm{mV}$, horizontal scale-bar to $10 \mathrm{~ms}$. HFS, high-frequency stimulation; LTP, long-term potentiation; s.c., subcutaneously; PS, population spike.

$P<0.05$, Figure 4a; fEPSP: $F(1,352)=6.145, P<0.05$; not shown). Thus, systemic application of rolipram facilitates STP into LTP independent of changes in basal synaptic transmission.

PDE4 inhibition rescues object recognition memory 1 week after MK801 treatment. There were no significant differences in absolute exploration levels between the different groups during $\mathrm{T} 1 \quad(\mathrm{~F} \quad(3,36)=0.209, \quad N S$; Figure $5 b)$, nor during T2 $(F(3,36)=1.364$, NS; Figure $5 c)$.

One week after i.p. treatment with MK801 $(n=10)$, object recognition memory performance was significantly impaired, as no difference between time spent exploring the familiar and the novel objects could be observed $(F(1,18)=0.213$, NS; Figure $5 e)$. In contrast, the control group $(n=10)$, treated with saline 1 week before behavioral testing, clearly distinguished between the familiar and the novel objects $4 \mathrm{~h}$ after T1 ( $\mathrm{F}$ $(1,18)=13.813, P<0.01$; Figure $5 d)$.

If rolipram was injected s.c. $24 \mathrm{~h}$ before T2, vehicle- $(n=10)$ and MK801-treated animals $(n=8)$, both significantly remembered the familiar object after $4 \mathrm{~h}(\mathrm{~F}(1,18)=60.691$, $P<0.0001$ and $F(1,14)=8.078, \quad P<0.01$, respectively; Figures $5 f$ and g, respectively). Thus, treatment with rolipram prevented MK801-induced deficits in object recognition memory. 
a
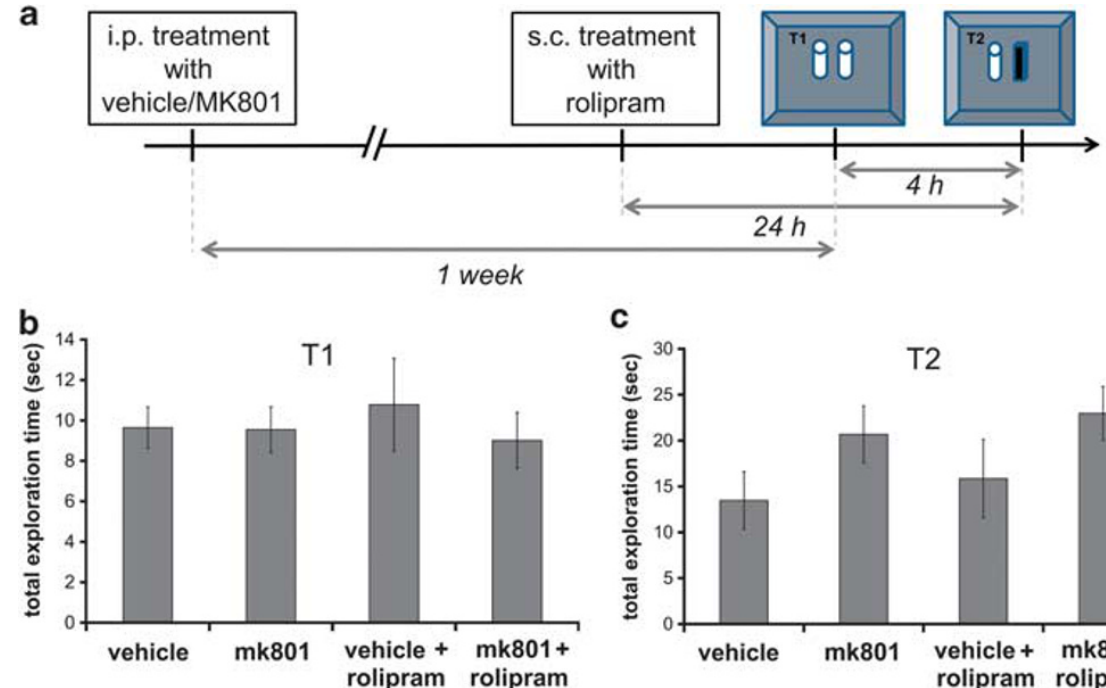

C
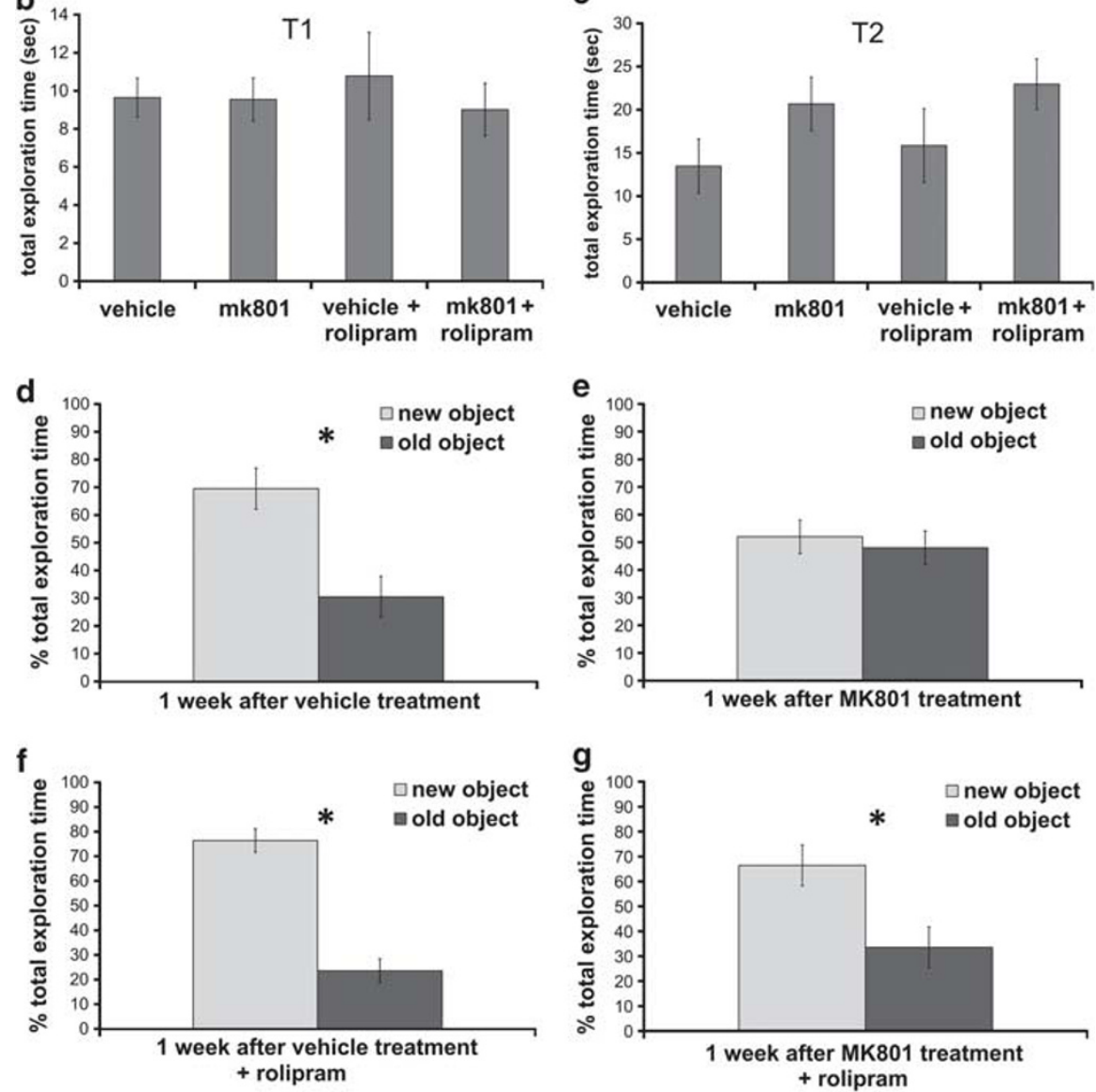

Figure 5 PDE4 inhibition rescues impaired object recognition memory in MK801-treated animals. (a) Timeline and experimental design of the ORT study. During the T1 the animal is allowed to explore two identical objects. $4 \mathrm{~h}$ later in the T2, the animal is exposed to a familiar and a novel object. Subcutaneous (s.c.) rolipram injection was applied $24 \mathrm{~h}$ before T2. i.p. treatment with MK801 or vehicle occurred 1 week before T1. (b) During T1 absolute exploration time was comparable between all groups. Values represent means \pm s.e.m. (c) During T2 absolute exploration levels did not differ significantly between the four groups. Values represent means \pm s.e.m. ${ }^{*} P<0.05$. (d) In the control group, 1 week after i.p. treatment with vehicle, the animals still remember the old object after $4 \mathrm{~h}$, as shown by a significantly longer exploration time of the novel object during T2. Values represent means \pm s.e.m.; ${ }^{*} P<0.05$. (e) Animals treated with MK801 1 week before the ORT do not remember the familiar object after $4 \mathrm{~h}$, as indicated by equal exploration times of both objects. (f) Control animals, which were treated with vehicle 1 week before the ORT, show a significant memory performance, following rolipram injection $24 \mathrm{~h}$ before T2. (g) MK801-induced memory impairment is prevented if animals are given rolipram $24 \mathrm{~h}$ before T2. i.p., intraperitoneal; ORT, object recognition task; PDE4, phosphodiesterase type 4; s.c., subcutaneously; T1, first trial; T2, second trial.

\section{Discussion}

The present study demonstrates that PDE4 inhibition facilitates hippocampal LTP in freely behaving healthy animals after intracerebroventricular (i.c.v.) as well as after systemic (s.c.) administration, and that it rescues long-term impairments in LTP and in object recognition memory that occur in an animal model of psychosis.

Phosphodiesterases (PDEs) are enzymes that break down cyclic nucleotides, and have an important role in intracellular signaling. Hence, PDE inhibitors elevate concentrations of second messengers, such as cAMPs and cyclic guanosine monophosphates (cGMPs), thereby affecting major intracellular cascades involved in synaptic plasticity. ${ }^{43}$ The activity of PKA is determined by CAMP, and PKA mediates factors such as $\mathrm{CREB}^{4}$ that triggers gene transcription, which is in turn essential for long-lasting LTP and memory. ${ }^{5,37}$ Rolipram is known to selectively inhibit CAMP-specific PDE4 and to increase cAMP levels by preventing its hydrolysis. ${ }^{2,3,38,39}$ Our results support that this is also the case when rolipram is injected in vivo: i.c.v. injection of rolipram increases the hippocampal cAMP concentration. Rolipram activates the 
mitogen-activated protein kinase (MAPK) pathway via Rap1 but not Ras signaling. ${ }^{35}$ Treatment with rolipram also increases hippocampal expression and phosphorylation of CREB. ${ }^{40,41}$ Therefore, the cAMP/PKA/MAPK/CREB pathway appears to be specifically involved in the rolipram-mediated effects on synaptic plasticity and memory.

Behavioral studies have demonstrated an improving effect of rolipram in memory-related tasks. ${ }^{42,43}$ Rolipram also enhances synaptic plasticity in the hippocampal slice preparation..$^{2,6,35}$ Our study is the first one to complete this picture of evidence, in vivo, by demonstrating that PDE4 inhibition also facilitates hippocampal LTP in the intact brains of freely behaving rats.

Although primarily known from the neuroenhancement research area ${ }^{44}$ and from aborted clinical trials as an antidepressant, ${ }^{45,46}$ recent behavioral studies indicate a possible therapeutic role of PDE4 inhibition in psychosisrelated diseases. ${ }^{21,29}$ On the molecular level, common antipsychotics primarily block the dopamine $D_{2}$-receptors and thereby cause an increase in CAMP, ${ }^{21,47}$ implying a possible therapeutic potential for CAMP-concentration-elevating PDE inhibitors in schizophrenia spectrum disorders. Of note, no currently available antipsychotics are able to treat schizophrenia-related cognitive dysfunctions. ${ }^{48}$ In this respect, PDE4 might be a more promising target.

In this study, we demonstrated that PDE4 inhibition prevents MK801-induced long-term deficit in the ability to express LTP in freely moving rats. Through application of rolipram 1 week after MK801 treatment, LTP was enabled that lasted for over $24 \mathrm{~h}$. Specifically, the maintenance phase was fully rescued. This is in line with the finding that cAMP has a role primarily in the later phase of LTP, ${ }^{49}$ as well as in long-term rather than in short-term memory. ${ }^{1}$ In parallel, demonstrating a functional aspect of these electrophysiological findings, we found that a single MK801 treatment leads to long-term impairments in object recognition memory and that PDE4 inhibition prevents these MK801-induced memory deficits. In our behavioral study, animals were treated with rolipram $20 \mathrm{~h}$ before the first trial of the ORT. Thus, the ability of rolipram to prevent MK801induced deficit in object recognition memory lasted far beyond its half-life time of $1-3 \mathrm{~h} .{ }^{50}$ Others have already demonstrated persistent effects of subchronic ${ }^{1,40}$ and chronic ${ }^{41,51}$ rolipram treatment. Our behavioral and electrophysiological results indicate that an acute injection with rolipram is sufficient to trigger molecular changes related to memory and synaptic plasticity lasting for more than $20 \mathrm{~h}$. Presumably, this happens via activation of CREB-dependent gene expression.

Besides suggesting a possible therapeutic target, these findings also give us insights into potential pathophysiological mechanisms underlying schizophreniform psychosis. Why are plasticity and object recognition memory still impaired 1 week after an acute MK801-induced psychotic event? Which mechanisms lead to the ability of PDE4 inhibition to restore it? Our animal model is based on the NMDAR-hypofunction hypothesis of schizophrenia, ${ }^{52,53}$ which assumes that a deficiency in NMDAR functioning has a major role in schizophreniform pathology. If given systemically, MK801 increases spontaneous firing rates in the medial prefrontal cortex, specifically via a hippocampo-prefrontal pathway. ${ }^{54}$ Thus, among these two main schizophrenia-related brain structures, the medial prefrontal cortex and the hippocampus, the latter seems to be activated first by MK801. However, presumably effects within both regions and their circuits lead to the overall psychotomimetic profile of MK801. After a single application of MK801, a high proportion of NMDARs are irreversibly blocked. ${ }^{55}$ This treatment results in a physiological long-term change, which lasts for at least 1 week, as reflected by the impairment of synaptic plasticity and object recognition memory that we have observed in our study. The mechanism underlying this effect may relate to NMDAR hypofunction resulting from a loss of receptors but also to a functional impairment of the receptor itself. This possibility is supported by findings that increasing available glycine rescues impaired LTP in the same MK801 animal model. ${ }^{17}$ However, our current finding that impaired LTP is also rescued by PDE4 inhibition suggests that alterations of the cAMP concentration in the brain might additionally have an important role in this phenomenon. Indeed, some evidence exists for a possible direct link between NMDARs and cAMP levels. For instance, Skeberdis et al. ${ }^{56}$ have shown that PKA regulates $\mathrm{Ca}^{2+}$-influx through NMDARs in vitro. Specifically, this study demonstrated that the $\mathrm{Ca}^{2+}$ permeability of neuronal NMDARs is controlled by the CAMP-PKA signaling cascade. PKA inhibition led to a decreased NMDAR-mediated $\mathrm{Ca}^{2+}$-rise in activated dendritic spines, indicating that PKA might also have a role in the regulation of both the induction and maintenance of LTP.

Another interesting link in this respect is provided by the fact that the NR1 subunit of the NMDAR is phosphorylated by PKA at the $\mathrm{S} 897$ site and that mice deficient for this phosphorylation display a schizophrenia-relevant behavioral profile. ${ }^{57}$ Additionally, the phosphorylation at this site has been shown to be reduced in schizophrenic patients. ${ }^{58}$ Zhang et al., ${ }^{28,59}$ have shown that inhibition of PDE4 reverses memory deficits associated specifically with NMDAR antagonism. Moreover, PDE4 inhibitor rolipram has been demonstrated to enhance the ability of NMDA to increase cAMP in neurons. This effect could be antagonized by application of MK801. ${ }^{60}$ Finally, it has been recently reported that CAMP production is modulated by PDE4 in response to NMDAR stimulation via a pharmacological NMDAR agonist in mouse cortical neurons, thereby providing another link between NMDAR-functioning and PDE4 (source: schizophrenia research forum website). ${ }^{61}$

Despite these first pieces of evidence, it remains speculative as to whether CAMP levels depend on the NMDAR, if they change as a consequence of NMDAR hypofunction, or if cAMP itself has a causative role in this respect by influencing NMDAR currents. It is furthermore unclear if PDE4 inhibition rescues MK801-induced deficits by 'kicking-in' at a more downstream level of NMDAR-dependent signaling cascades, leaving the dysfunctional upstream part unaffected, or if elevated cAMP levels directly interact with NMDARs, thereby restoring relevant cascades at an early phase of the process. The latter point is supported by in vitro data that suggest that PDE4 and DISC1 associate with NR1, a mandatory NMDAR-subunit (source: schizophrenia research forum website. $)^{61}$

In order to further study the therapeutic potential of PDE4 inhibition, it is important to see if rolipram would display similar 
effects on hippocampal synaptic plasticity after a peripheral application. We show here that a systemic injection of rolipram has similar beneficial effects as an application directly into the brain. Behavioral studies have already indicated that systemic application of rolipram leads to an enhanced effect on cognitive performance, ${ }^{1,2,41}$ and our study suggests a possible mechanism underlying this effect: namely, facilitation of hippocampal synaptic plasticity. Our data support that, after peripheral administration in vivo, rolipram reaches the hippocampus, the brain structure that is most prominently involved in learning and memory processes, and facilitates its ability to express LTP on the cellular level. Interestingly, a high-dose subcutaneous injection induced a transient potentiation of PS, suggesting that a brief increase in somatic excitability occurred. This finding is interesting in its own right as it suggests that rolipram is able to enhance cellular excitability in the absence of external electrical stimulation. Higher doses of rolipram could be expected to prolong the duration of this chemical potentiation, and this may also have interesting therapeutic implications.

Nonetheless, although PDE4 inhibition displays an interesting new target with neuroenhancing and therapeutic potential and although rolipram provides a valuable tool in order to study this mechanism of action, this particular substance has to be first pharmacologically tuned in order to make it relevant for clinical consideration. A known side-effect of rolipram is nausea. ${ }^{46}$ And indeed, we also observed transient dizziness in our rats right after a systemic injection of the higher dose of rolipram. This emetic effect makes it rather difficult to test rolipram in human trials. Additionally, as molecular evidence has shown specifically PDE4B to be a genetic susceptibility factor for schizophrenia, ${ }^{23}$ more subtype-selective PDE4 inhibitors would be interesting to study in future.

In conclusion, our results support that treatment with a PDE4 inhibitor facilitates synaptic plasticity in the intact brains of healthy animals and restores impaired LTP and object recognition memory in an animal model of psychosis. These data provide further insight into possible mechanisms underlying psychosis pathology. We suggest that the antipsychoticlike profile of PDE4 inhibition is mediated, in part, by a rescue of impaired LTP that enables improved hippocampus-dependent cognition.

\section{Conflict of interest}

The authors declare no conflict of interest.

Acknowledgements. We thank Jens Klausnitzer for technical assistance, Nadine Gomell for animal care and Prof Dr Doris Koesling, as well as Isabel Schönle for support and advice on the RIA experiments. VW is a scholarship recipient of the International Graduate School of Neuroscience (IGSN) of the Ruhr University.

1. Rutten K, Prickaerts J, Schaenzle G, Rosenbrock H, Blokland A. Sub-chronic rolipram treatment leads to a persistent improvement in long-term object memory in rats. Neurobiol Learn Mem 2008; 90: 569-575.

2. Barad M, Bourtchouladze R, Winder DG, Golan H, Kandel E. Rolipram, a type IV-specific phosphodiesterase inhibitor, facilitates the establishment of long-lasting long-term potentiation and improves memory. Proc Natl Acad Sci USA 1998; 95: 15020-15025.
3. van Staveren WC, Markerink-van Ittersum M, Steinbusch HW, de Vente J. The effects of phosphodiesterase inhibition on cyclic GMP and cyclic AMP accumulation in the hippocampus of the rat. Brain Res 2001; 888: 275-286.

4. Waltereit R, Weller M. Signaling from cAMP/PKA to MAPK and synaptic plasticity. Mol Neurobiol 2003; 27: 99-106

5. Barco A, Pittenger C, Kandel ER. CREB, memory enhancement and the treatment of memory disorders: promises, pitfalls and prospects. Expert Opin Ther Targets 2003; 7: $101-114$.

6. Navakkode S, Sajikumar S, Frey JU. The type IV-specific phosphodiesterase inhibitor rolipram and its effect on hippocampal long-term potentiation and synaptic tagging. $J$ Neurosci 2004; 24: 7740-7744.

7. Bliss TV, Lomo T. Long-lasting potentiation of synaptic transmission in the dentate area of the anaesthetized rabbit following stimulation of the perforant path. J Physiol 1973; 232: 331-356.

8. Bliss TV, Collingridge GL. A synaptic model of memory: long-term potentiation in the hippocampus. Nature 1993; 361: 31-39.

9. Kemp A, Manahan-Vaughan D. Hippocampal long-term depression: master or minion in declarative memory processes? Trends Neurosci 2007; 30: 111-118.

10. Douki S, Taktak MJ, Ben Zineb S, Cheour M. Therapeutic strategies in the first psychotic episode. Encephale 1999; 25(Spec No 3): 44-51.

11. McGorry PD, Killackey E, Yung A. Early intervention in psychosis: concepts, evidence and future directions. World Psychiatry 2008; 7: 148-156.

12. Goldner-Vukov M, Cupina DD, Moore LJ, Baba-Milkiæ N, Milovanoviæ S. Early intervention in first episode psychosis: hope for a better future. Srp Arh Celok Lek 2007; 135: $672-678$.

13. Birchwood M, Todd $P$, Jackson $C$. Early intervention in psychosis. The critical period hypothesis. Br J Psychiatry Supp/ 1998; 172: 53-59.

14. Bird V, Premkumar P, Kendall T, Whittington C, Mitchell J, Kuipers E. Early intervention services, cognitive-behavioural therapy and family intervention in early psychosis: systematic review. Br J Psychiatry 2010; 197: 350-356.

15. Wöhrl R, Eisenach S, Manahan-Vaughan D, Heinemann U, von Haebler D. Acute and long-term effects of MK-801 on direct cortical input evoked homosynaptic and heterosynaptic plasticity in the CA1 region of the female rat. Eur J Neurosci 2007; 26: 2873-2883.

16. Manahan-Vaughan D, von Haebler D, Winter C, Juckel G, Heinemann U. A single application of MK801 causes symptoms of acute psychosis, deficits in spatial memory, and impairment of synaptic plasticity in rats. Hippocampus 2008; 18: 125-134.

17. Manahan-Vaughan D, Wildförster V, Thomsen C. Rescue of hippocampal LTP and learning deficits in a rat model of psychosis by inhibition of glycine transporter-1 (GlyT1). Eur J Neurosci 2008; 28: 1342-1350.

18. Lahti AC, Weiler MA, Tamara Michaelidis BA, Parwani A, Tamminga CA. Effects of ketamine in normal and schizophrenic volunteers. Neuropsychopharmacology 2001; 25: 455-467.

19. Tamminga CA, Holcomb HH, Gao XM, Lahti AC. Glutamate pharmacology and the treatment of schizophrenia: current status and future directions. Int Clin Psychopharmacol 1995; 10(Suppl 3): 29-37.

20. Davis JA, Gould TJ. Rolipram attenuates MK-801-induced deficits in latent inhibition. Behav Neurosci 2005; 119: 595-602.

21. Kanes SJ, Tokarczyk J, Siegel SJ, Bilker W, Abel T, Kelly MP. Rolipram: a specific phosphodiesterase 4 inhibitor with potential antipsychotic activity. Neuroscience 2007; 144: 239-246.

22. Millar JK, Mackie S, Clapcote SJ, Murdoch H, Pickard BS, Christie S et al. Disrupted in schizophrenia 1 and phosphodiesterase 4B: towards an understanding of psychiatric illness. J Physiol 2007; 584(Pt 2): 401-405.

23. Millar JK, Pickard BS, Mackie S, James R, Christie S, Buchanan SR et al. DISC1 and $\mathrm{PDE} 4 \mathrm{~B}$ are interacting genetic factors in schizophrenia that regulate $\mathrm{CAMP}$ signaling. Science 2005; 310: 1187-1191.

24. Blackwood DH, Fordyce A, Walker MT, St Clair DM, Porteous DJ, Muir WJ. Schizophrenia and affective disorders-cosegregation with a translocation at chromosome 1q42 that directly disrupts brain-expressed genes: clinical and P300 findings in a family. Am J Hum Genet 2001; 69: 428-433.

25. Sachs NA, Sawa A, Holmes SE, Ross CA, DeLisi LE, Margolis RL. A frameshift mutation in Disrupted in Schizophrenia 1 in an American family with schizophrenia and schizoaffective disorder. Mol Psychiatry 2005; 10: 758-764.

26. Sawa A, Snyder SH. Genetics. Two genes link two distinct psychoses. Science 2005; 310: 1128-1129.

27. Mackie S, Millar JK, Porteous DJ. Role of DISC1 in neural development and schizophrenia Curr Opin Neurobiol 2007; 17: 95-102.

28. Zhang HT, Crissman AM, Dorairaj NR, Chandler LJ, O'Donnell JM. Inhibition of cyclic AMP phosphodiesterase (PDE4) reverses memory deficits associated with NMDA receptor antagonism. Neuropsychopharmacology 2000; 23: 198-204.

29. Siuciak JA, Chapin DS, McCarthy SA, Martin AN. Antipsychotic profile of rolipram: efficacy in rats and reduced sensitivity in mice deficient in the phosphodiesterase-4B (PDE4B) enzyme. Psychopharmacology 2007; 192: 415-424.

30. Manahan-Vaughan D, Braunewell KH, Reymann KG. Subtype-specific involvement of metabotropic glutamate receptors in two forms of long-term potentiation in the dentate gyrus of freely moving rats. Neuroscience 1998; 86: 709-721. 
31. Romón T, Mengod G, Adell A. Expression of parvalbumin and glutamic acid decarboxylase-67 after acute administration of MK-801. Implications for the NMDA hypofunction model of schizophrenia. Psychopharmacology 2011; 217: 231-238.

32. Steiner AL, Parker CW, Kipnis DM. Radioimmunoassay for cyclic nucleotides. I. Preparation of antibodies and iodinated cyclic nucleotides. J Biol Chem 1972; 247: 1106-1113.

33. Harper JF, Brooker G. Femtomole sensitive radioimmunoassay for cyclic AMP and cyclic GMP after $2^{\prime} 0$ acetylation by acetic anhydride in aqueous solution. $J$ Cyclic Nucleotide Res 1975; 1: 207-218.

34. Prickaerts J, de Vente J, Honig W, Steinbusch HWM, Blokland A. cGMP, but not cAMP, in rat hippocampus is involved in early stages of object memory consolidation. Eur $J$ Pharmacol 2002; 436: 83-87.

35. Navakkode S, Sajikumar S, Frey JU. Mitogen-activated protein kinase-mediated reinforcement of hippocampal early long-term depression by the type IV-specific phosphodiesterase inhibitor rolipram and its effect on synaptic tagging. J Neurosci 2005 25: 10664-10670.

36. Navakkode S, Korte M. Cooperation between cholinergic and glutamatergic receptors are essential to induce BDNF-dependent long-lasting memory storage. Hippocampus 2011; 22: 335-346, doi: 10.1002/hipo.20902.

37. Sweatt JD. The neuronal MAP kinase cascade: a biochemical signal integration system subserving synaptic plasticity and memory. J Neurochem 2001; 76: 1-10.

38. Beavo JA. Multiple isozymes of cyclic nucleotide phosphodiesterase. Adv. Second Messenger Phosphoprotein Res 1988; 22: 1-38.

39. Bender AT, Beavo JA. Cyclic nucleotide phosphodiesterases: molecular regulation to clinical use. Pharmacol Rev 2006; 58: 488-520.

40. Monti B, Berteotti C, Contestabile A. Subchronic rolipram delivery activates hippocampa CREB and arc, enhances retention and slows down extinction of conditioned fear. Neuropsychopharmacology 2006; 31: 278-286.

41. Li Y, Cheng Y, Huang Y, Conti M, Wilson SP, O'Donnell JM et al. Phosphodiesterase-4D knock-out and RNA interference-mediated knock-down enhance memory and increase hippocampal neurogenesis via increased cAMP signaling. J Neurosci 2011; 31: 172-183.

42. Rutten K, Basile JL, Prickaerts J, Blokland A, Vivian JA. Selective PDE inhibitors rolipram and sildenafil improve object retrieval performance in adult cynomolgus macaques. Psychopharmacology 2008; 196: 643-648.

43. Reneerkens $\mathrm{OAH}$, Rutten K, Steinbusch HWM, Blokland A, Prickaerts J. Selective phosphodiesterase inhibitors: a promising target for cognition enhancement. Psychopharmacology 2009; 202: 419-443.

44. Normann C, Berger M. Neuroenhancement: status quo and perspectives. Eur Arch Psychiatry Clin Neurosci 2008; 258(Suppl 5): 110-114.

45. Zeller E, Stief HJ, Pflug B, Sastre-y-Hernández M. Results of a phase II study of the antidepressant effect of rolipram. Pharmacopsychiatry 1984; 17: 188-190.

46. Hebenstreit GF, Fellerer K, Fichte K, Fischer G, Geyer N, Meya U et al. Rolipram in major depressive disorder: results of a double-blind comparative study with imipramine. Pharmacopsychiatry 1989; 22: 156-160.

47. Halene TB, Siegel SJ. Antipsychotic-like properties of phosphodiesterase 4 inhibitors: evaluation of 4-(3-butoxy-4-methoxybenzyl)-2-imidazolidinone (RO-20-1724) with auditory event-related potentials and prepulse inhibition of startle. J Pharmacol Exp Ther 2008; 326: 230-239.

48. Carpenter WT, Koenig Jl. The evolution of drug development in schizophrenia: past issues and future opportunities. Neuropsychopharmacology 2008; 33: 2061-2079.

49. Frey U, Huang YY, Kandel ER. Effects of cAMP simulate a late stage of LTP in hippocampal CA1 neurons. Science 1993; 260: 1661-1664.

50. Krause W, Kühne G. Pharmacokinetics of rolipram in the rhesus and cynomolgus monkeys, the rat and the rabbit. Studies on species differences. Xenobiotica 1988; 18: 561-571.

51. Gong B, Vitolo OV, Trinchese F, Liu S, Shelanski M, Arancio O. Persistent improvement in synaptic and cognitive functions in an Alzheimer mouse model after rolipram treatment. $J$ Clin Invest 2004; 114: 1624-1634.

52. Lisman JE, Coyle JT, Green RW, Javitt DC, Benes FM, Heckers S et al. Circuit-based framework for understanding neurotransmitter and risk gene interactions in schizophrenia. Trends Neurosci 2008; 31: 234-242.

53. Gordon JA. Testing the glutamate hypothesis of schizophrenia. Nat Neurosci 2010; 13: $2-4$.

54. Jodo E, Suzuki Y, Katayama T, Hoshino K, Takeuchi S, Niwa S et al. Activation of medial prefrontal cortex by phencyclidine is mediated via a hippocampo-prefrontal pathway. Cereb Cortex 2005; 15: 663-669.

55. Rosenmund C, Clements JD, Westbrook GL. Nonuniform probability of glutamate release at a hippocampal synapse. Science 1993; 262: 754-757.

56. Skeberdis VA, Chevaleyre V, Lau CG, Goldberg JH, Pettit DL, Suadicani SO et al. Protein kinase A regulates calcium permeability of NMDA receptors. Nat Neurosci2006; 9: 501-510.

57. Li B, Devidze N, Barengolts D, Prostak N, Sphicas E, Apicella AJ et al. NMDA receptor phosphorylation at a site affected in schizophrenia controls synaptic and behavioral plasticity. J Neurosci 2009; 29: 11965-11972.

58. Emamian ES, Karayiorgou M, Gogos JA. Decreased phosphorylation of NMDA receptor type 1 at serine 897 in brains of patients with Schizophrenia. J Neurosci 2004; 24: 1561-1564.

59. Zhang H, Huang Y, Suvarna NU, Deng C, Crissman AM, Hopper AT et al. Effects of the novel PDE4 inhibitors MEM1018 and MEM1091 on memory in the radial-arm maze and inhibitory avoidance tests in rats. Psychopharmacology 2005; 179: 613-619.

60. Suvarna NU, O'Donnell JM. Hydrolysis of N-methyl-D-aspartate receptor-stimulated cAMP and CGMP by PDE4 and PDE2 phosphodiesterases in primary neuronal cultures of rat cerebral cortex and hippocampus. J Pharmacol Exp Ther 2002; 302: 249-256.

61. Rampino A. DISC 2010 - protein with many talents. Schizophrenia Research Forum website, 5 November 2010, accessed 10 April 2011. Available from: http://www. schizophreniaforum.org/new/detail.asp?id $=1632$.

Translational Psychiatry is an open-access journal published by Nature Publishing Group. This work is licensed under the Creative Commons Attribution-Noncommercial-No Derivative Works 3.0 Unported License. To view a copy of this license, visit http://creativecommons.org/licenses/by-nc-nd/3.0/ 